\title{
INTRODUCTION
}

\section{(De)Constructing Martial Arts (Studies)}

\section{Deconstructing What?}

First things first. What are martial arts? What do we mean when we say 'martial arts'? These two questions can be regarded as either very similar to each other or very different. Simplifying in the extreme, we might propose that, although there is a spectrum of possible answers, there are two main positions on these matters. On the one hand, there is a kind of strict or rigorously literalist position, which holds that only certain kinds of things can properly be regarded as martial arts, and that to fit the bill they must meet certain criteria, such as having been designed for or used on the battlefield, or being some (implicitly bodily) part of the 'arts of war'. On the other hand, there is an ostensibly more relaxed, 'loose' or open-ended position, which might either be called cultural, 'discursive', or (pejoratively) 'relativist'. This holds that, because all of the terms and concepts that we use are variable conventional constructs, a category like 'martial arts' only ever refers to whatever people think and say are 'martial arts'. Both the category and the practices are heavily cultural and contextual.

There are strong criticisms of both positions. The literalist position tends to exclude a great many practices that are widely recognised as martial arts. Literalist positions may not accept that judo, taijiquan (aka tai chi or taiji), aikido or even MMA, for instance, should be regarded as martial arts, for a range of reasons (all boiling down to the idea that they were not developed specifically with the battlefield in mind). So, they would be excluded from attention, even though many other people, in line with conventional usage, would be happy to apply the term 'martial arts' to them. In other words, strict or rigorous literalist positions impose rigid criteria that exclude practices deemed to be 'too far' away from being martial arts 'proper' - such as practices that may focus on health cultivation, esoteric matters, or even practices with 'too much' of a focus on sport or personal development. In being fixated on war or battle,

How to cite this book chapter:

Bowman, P. 2019. Deconstructing Martial Arts. Pp. 1-17. Cardiff: Cardiff University

Press. DOI: https://doi.org/10.18573/book1.a. License: CC-BY-NC-ND 4.0 
a literalist position might even exclude the range of practices that make up the brutal world of full contact combat sports, such as MMA. Accordingly, one criticism of literalist positions is that in their quest for rigour and precision they can effectively become self-blinding or myopic positions which, in their putative insistence on 'reality', somewhat ironically end up refusing to accept what many (or most) others take to be reality - at least the lived reality of what people think of and do 'as' martial arts in a given culture or society at a given time.

Meanwhile, a culturalist or discursive position can be subject to the criticism that it is too 'relativist' or too open or flexible to be meaningful. In his important discussion of the problem of establishing a 'concept' of martial arts, Benjamin N. Judkins examines a range of scholarly approaches to martial arts and proposes that, when it comes to 'discursive' understandings of martial arts, 'selfidentification is a poor metric to judge what activities qualify as a martial art, or how we as researchers should structure our comparative case studies'. To his mind, 'this has always been a potential weakness of the sociological approach'; so, he asks, 'lacking a universally agreed upon definition, how should we move forward?' (Judkins 2016a, 9)

Judkins himself moves forward by pointing out that definition is not really the question. The question is really one of why we are studying this possible object or field called 'martial arts' in the first place. In his discussion, Judkins deconstructs the ways in which different kinds of attempts to define or even demarcate the category of martial arts tend to fall down or unravel. For instance, he notes that it is not possible to separate off 'military' from 'civilian' combat training or practices, as the likes of Donn Draeger once attempted to do. No cultural or social category is hermetically sealed. Each is always, effectively or potentially, connected to and even infused with elements of others. Military and civilian realms may seem to be poles apart, and, in many respects, they often can be. But, as the history of the development of martial arts in the US shows us, the growth of civilian and police 'martial arts' practice was often indebted to and driven by returning servicemen (Krug 2001). The US is the big example, but other Western countries have similar narratives. The civilian/ military distinction is even murkier in Asian countries, where martial arts narratives are replete with tales of civilian pioneers entering military life and vice versa (see for example Gillis 2008 for a fascinating set of stories).

In his next move, following Peter Lorge's influential discussion of martial arts in China, Judkins points out that even prominent Chinese military generals have (in)famously dismissed the martial utility of unarmed combat training (Judkins 2016a, 7-8; cf. Lorge 2012, 3-4). This may seem ironic. However, the real irony is that many of these 'dismissive' generals nonetheless continued to advocate the importance of unarmed combat training for their soldiers despite their conviction that unarmed combat training was not directly useful in war. This is because the importance of such 'useless' training derived from the sense that combat training builds character, resilience and spirit. 
All of this complicates things further. Indeed, it could be said to make the whole literalist position fall to pieces - not least because of the possibility that things as 'non-martial' as intense aerobic exercise, on the one hand, or meditation, on the other, might be of more 'combat value' than literal combat training itself.

Many modern martial artists will recognise this idea. In technical (and polite) Chinese terms, this is the distinction between 'gong' and 'fa', or the deep skill, energy, force and sensitivity required (gong) to make what are otherwise merely the external semblance (fa) of techniques 'work' (Nulty 2017). In more general terms, how many times have martial arts practitioners looked at the demonstration of a technique and said or thought something like 'that would never work, at least not if you did it like that'? The sense is that what is more important in combat is an intensity and single-minded determination of purpose (spirit). How many of us have ever suspected, as I have, that in a dangerous situation it would be preferable to have an ultra-competitive ice-hockey, rugby or American football player on one's side than a serene old tenth dan who can do amazing technical things but has never had a real fight? This is not simply a prejudice based on doubting someone's ability. It is an intuition that someone who is used to intense physical competition will be more able to deal with non-compliant opponents and to handle what Miller calls the 'chemical dump' that explodes in our bodies in situations of extreme stress (Miller 2008; Miller and Eisler 2011).

Certain forms of ('non-martial') intense exercise popular today involve dealing with equivalent if not identical physical and psychological stresses, training with as much 'spirit' as possible and taking the body to the limits of exhaustion in different ways. Because of their physiological and often psychological similarity to what happens to a person in a physical conflict or confrontation, these intense exercise programmes are sometimes wholeheartedly embraced, advocated by, or included in military and/or 'reality-based' martial arts such as krav maga for precisely this 'combat-like' reason. On the flipside, as is more well-known (or more widely believed), ultra-slow movement or static meditation practices emphasize and 'train' qualities like relaxed precision and calm detachment, and they have long been associated with the generation of both budō 'fighting spirit' and - 'paradoxically' - the cultivation of a peaceful outlook (Benesch 2016; see also Reid and Croucher 1984).

As a long-time reader of the work of the deconstructive philosopher Jacques Derrida, what shines out from all of this is the extent to which practices (if not ideas) of 'the martial' or 'martial art' seem constantly to be supplemented by non-martial - or not literally martial - elements (Derrida 1976; see also Bowman 2008). In Derrida's work, the notion of the supplement is deployed to demonstrate the ways that things we tend to want to consign to the category of the secondary, the add-on, the non-essential, the extra, and so on, are actually in a very real sense 'primary' (Bennington and Derrida 2008). Or else, put 
differently, there is no 'primary', no 'essence', no 'pure', despite our desire for this to be so. Rather, there are only ever supplementary ingredients, practices or procedures. The idea of the 'essence' is itself an effect - a kind of illusion, or even delusion (Derrida 1998).

Of course, this is not to say that the 'essence effect' is somehow fake. Imagine your ideal martial arts class. Practitioners may think of a martial arts training session which starts or ends with some kind of meditation, then breath training, then physical exercises for strength or flexibility, then maybe forms training, then applications, then ever freer sparring, maybe also weapons, until they may have felt that they were 'really' doing 'real fighting'. We might come away from such sessions feeling that we really have experienced the essence of martial arts training. And maybe we did experience something profound. But the point is that the experience of what we think of as one thing is always a subjective experience of multiple supplementary elements being brought together in a certain way.

This is so even if we think that it is only 'one thing' that we are doing. Whether we are doing standing qigong training or some kind of real-world combat scenario training, we are never simply doing 'one thing. Each of these supposedly unitary activities is made up of myriad supplementary components, each of which could be ever further dissected and divided up into ever more differentiated elements. But, because we have a sense of ourselves as unitary, and because we have to use shared languages, we are always inclined (or required) to simplify things so that heterogeneity and multiplicity are given one name and imagined as having one essence.

This might help explain why practitioners of certain martial arts styles feel most strongly (often negatively, or critically) not about different styles but about practitioners of 'the same' style - what they regard as 'their style' - who practice differently and 'therefore', they believe, wrongly. Different practitioners with different approaches to training in different schools and clubs of the 'same style' can easily regard each other's approaches as 'wrong' because each will feel that the essence of the style cannot be conveyed other than via the correct practices - their practices.

At issue is the inevitable emergence of difference within putative or nominal sameness (Derrida 1988). Styles and systems cannot but change, from teacher to teacher, and even over time under the same teacher; because styles and systems are not fixed essences but rather constructs. They are constructed through constantly changing practices and combinations of elements. They are constructs, not essences. Linguistic terms and imaginations work in many ways to try to persuade us that this or that martial art is always one thing. But, to put it bluntly, it is never one thing.

Hence, it is heartening that more and more scholars today are prepared to move away from making direct ontological or essentialist (what I earlier called 'literalist') statements about what this or that martial art 'is' or indeed what martial arts 'are'. The very category 'martial art' or 'martial arts' is first 
and foremost a contemporary construct. It has a history. It is only within the last few decades that the notion of 'martial art' has become an intelligible term that is widely understood as the kind of thing we all tend to think it means (Farrer and Whalen-Bridge 2011; Judkins 2014a). What non-specialists tend to think the term 'martial arts' means frequently involves some vague evocation of punching and kicking, coming from Asia, and - surprisingly frequently, still, half a century after their heyday - being exemplified by figures like Bruce Lee or Jackie Chan, whose very names have become shorthand for 'martial arts' (or 'kung fu').

Contemporary martial arts studies scholars have attempted to negotiate the variably and changeably constructed character of the practices, as well as the terms and categories we have available for conceptualising them, in various ways (Tan 2004; Bennett 2015; Judkins and Nielson 2015; Moenig 2015). In an opposite but effectively identical approach (that may be regarded as controversial because of its barefaced straightforwardness), the historian Peter Lorge elected to study the place of unarmed and armed combat training practices via the historical texts about them throughout Chinese history without excessively problematizing the term 'martial arts' at all. Lorge preferred to proceed in terms of a sense of the obviousness of the object to be analysed (Lorge 2012).

Following what is 'obviously' part of the thing under analysis is a valid route although the question immediately arises: Where do you draw the line? In studying this or that martial art, must we also study strength training, dietary practices, micro- and macro-ideologies, religious beliefs, and so on? What about the kinds of literature or television programmes that practitioners watch, or experienced in their formative years? As Derrida argued, context may be everything, and will always be incredibly important to understanding specific things, but when it comes to a context, how do you draw a line between what is inside and what is outside of a context? (Derrida 1988)

Indeed, a sense of the 'obviousness' of the object is the very thing that opens the door to all of the problems already discussed, and that Judkins has insightfully dissected (Judkins 2016a). For once you scratch the surface of what's 'obviously in' and 'obviously out' of our purview, everything becomes grey - and what Derrida would call 'undecidable. That is (to recall our earlier discussion of what is most useful), it may for instance be undecidable what is more important in krav maga training - how to handle a knife or how to keep going in the face of all terrors and adversities in a combat situation. The famously experienced author and self-defence instructor Rory Miller takes it even further. He states that, were you to be slapped in the face by a stranger, if you are the kind of person who would instantly feel outrage, anger and aggression, then he has little to nothing to teach you. You have already 'got it' - the key to self-defence a kind of righteous rage, and a capacity to retaliate ferociously (Miller 2008). If, however, you are someone who would freeze or feel fear, shock, confusion, even embarrassment, then perhaps he may never be able to teach you anything 
worthwhile. You may never 'get it'. You may always be incapacitated by fear, and you may always freeze. If this is true, then the question becomes one of whether therefore any pedagogy and hence any category akin to 'martial arts' is worthwhile on any 'literal' level.

This line of thinking opens out onto the possibility that there may be a 'myth of pedagogy' (Rancière 1991) that runs far deeper and wider than the familiar stories many martial artists know about instructors teaching absolute rubbish to hapless students who believe they are learning effective techniques or profound truths. If Miller's observation has any value, then perhaps the matters of teaching and learning in martial arts need to be rethought (Bowman 2016b). For the implication would seem to be that many people could never effectively 'learn' the most important aspect of self-defence - the aspect that might be called the ability to become a kind of berserker.

This is to evoke one of the most popular of myths that circulates among competitive fighters: That 'fighters are born, not made'. This is the idea that good fighters have an innate fighting spirit, and that unless you have this you cannot succeed as a fighter. Of course, a wide range of different kinds of evidence contradicts this enduring myth. The importance, and the palpable and measurable effects, of training strongly suggest that fighters are made, not born (Loïc Wacquant 2004, 2005, 2009).

Nonetheless, it is easy to get caught in an oscillation between accepting Miller's statement (and maybe also the myth of the natural born fighter), on the one hand, and believing in the more observable development of novices into experts, on the other. It is not uncommon to see uncoordinated, timid, non-aggressive and incompetent people entering the club on day one and their undergoing a complete physical and psychological transformation over time. (It may have happened to you. I think it may have happened to me, possibly, and more than once, at least partially.) Those who adhere to a 'natural born fighter' myth could argue that the person who entered on day one nonetheless had a 'spark' or 'hidden essence' that was cultivated. Others may retort that one does not need a spark or an essence, that all that is required is the desire, an effective teacher, and 'the means of correct training' (Foucault 1977).

But is this really the be-all and end-all of martial arts? Some readers will have noticed that this discussion has so far been presupposing one specific kind of outcome (effective self-defence skill) and conflating that with another ('being a fighter', either in the sense of fighting 'on the street' or doing competitive combat sports well). There is often a lot of conceptual drift and conflation in these waters. Despite its obviousness and familiarity, the range of meanings of 'martial arts' is not set in stone, and connotations frequently leach and bleed into each other. Certainly, not everyone enters a training hall or club for reasons of 'self-defence', 'competition' or 'fighting'. People may not even know their reasons. They may have more or less than one 'reason. There may be multiple vague attractions. It may just be 'something to do', perhaps to avoid something else. If there are reasons, these may oscillate between different possible outcomes, or 
merge and mutate. Reasons may change over time, emerging, receding, moving into and out of existence.

Scott Park Phillips offers an excellent overview of many of the most common reasons why people send their children to martial arts classes:

The most common reason people give for putting their children in martial arts classes is so that they will learn how to act with moral selfdiscipline. The list of qualities that the average parent wants their kid to learn in martial arts classes includes leadership, protecting the weak, legal and moral self-defense, overcoming challenges, persistence in the face of adversity, seeing the big picture, self-discipline, self-improvement, self-motivation, cooperation, teamwork, body confidence and awareness, love of exercise, learning from failures, and the ability to concentrate and focus. This is a lot of expectations to have! Why, if the main purpose of martial arts was fighting, would this ever have come about? The answer is simple: martial arts were always about more than fighting. (Phillips 2016, 29)

As he notes at the end of this list of common assumptions, this is a hell of a lot of reasons to train - or, more specifically, a hell of a lot of hopes and expectations (to project) about the outcomes of sending children to martial arts classes. And, as Phillips' final claim makes clear, this is because the term 'martial arts' is in many contemporary ways a misnomer: Martial arts are not about learning how to win a literal war - they are always about other things.

Does this mean that the term 'martial arts' today often functions as a kind of marketing tool to 'sell' exercise and self-development to children? There could certainly be some truth in this. After all, it can sometimes be easier to persuade children to find value in and do something by making cool-sounding associations: Big tough gorillas eat fruit; sharks eat fish and/or eating fish will make you clever; meat will give you big muscles; lions drink water; karate will make you tough; and so on. There is certainly some value in exploring this kind of intentional or accidental 'misrecognition' of one's own activities and investments. The psychoanalyst Jacques Lacan theorised misrecognition as inevitable and fundamental to the formation of identity and the workings of the symbolic order; later thinkers incorporated this idea into various theories of ideology (Althusser 1971; Silverman 1983; Lacan 2001). Indeed, throughout his provocative study, Phillips argues that martial arts - Chinese martial arts in particular - have for an extremely long time been misrecognised as principally or primarily martial when they are in fact much more a matter of art. Phillips' specific argument is that Chinese martial arts are at root the modern descendants or residues of ancient Chinese theatrical traditions (Phillips 2016).

Phillips' overall argument about 'possible origins' may be controversial, but his contention that martial arts are always about more and other than fighting is helpful. Sixt Wetzler has proposed that the most common range of 
reasons for attending martial arts classes include the following: 'Preparation for violent conflict', 'play', 'competition', 'performance', 'transcendent goals', and 'health care' (Wetzler 2015, 26). To this we might add the parental or vicariously projected categories set out by Phillips; and then the categories applicable to children made to take martial arts classes. These would include 'having been sent to classes as a child by parents' or 'having been made to do it at school until it just became "something that I do" and on, to the whole range of ex post facto rationalisations that could be invented and sincerely believed at any moment.

The point is that, in addition to the good reasons and good categories proposed by Wetzler, one should also remember the often less than good reasons and often less than good categories that also organise the 'decision' (or obligation, or automatism) to 'do' martial arts. Reasons given for martial art training can either be ex post facto rationalisations with no bearing on whatever true story there might be, or they may arise long into a period of training. In other words, one problem with Wetzler's proposed categories is that they are individualistic, rationalistic and 'Cartesian' - as if we are all Descartes and we wake up one day and say, 'I think [I am interested in transcendent goals and healthcare] therefore I am [going to go to practice kung fu, not krav maga]'. But the world does not work anything like as simply as that. Often, reasons are imposed, or generated, or simulated.

A friend once told me about something that would often happen in the kung fu class she attended. The instructor (or sifu) would at points sit the whole class down and proceed to give them a lecture on the philosophy that underpinned the art. When she told me this, I was horrified to hear about such a practice in a martial arts lesson. She said she certainly found it very frustrating and boring. We both agreed that surely not many people take martial arts classes for lectures, and that martial arts philosophy lectures did not really strike us as being an appropriate or valid part of martial arts classes as such.

Of course, the idea that at least some martial arts 'are philosophical' is widespread. Certainly, I am not saying that 'philosophy' is not present in martial arts, or in martial arts classes. Nor is it to say that martial arts - or indeed martial art classes - cannot or should not be philosophized. But all of these are very different things. To say that something 'is' philosophical begs the question of what we think we mean by that. Are we saying we can philosophize it - or about it? Or are we saying that it is itself an example of a philosophical thing? These are very different propositions. We might philosophize (about) anything, maybe everything. But is that the same as saying that everything is philosophical? (I explore this more fully in Chapter Six.)

What does philosophy even mean? Derrida spent a lot of time pondering matters such as this. To his mind, the conundrum of what is inside and what is outside philosophy was the core problem of philosophy itself. Inevitably, lots of philosophers (and non-philosophers) disagreed with him. Indeed, despite any 
evidence to the contrary, many philosophers still refuse to recognise Derrida as a philosopher.

Interestingly, as with 'martial arts', the questions of what philosophy is and what it is to do philosophy do not seem to have necessary or ineluctable answers either. People do different things and call it philosophy, and they disagree with what other people do under the title philosophy. This is the same as what happens in and around martial arts. At best, 'philosophy' (or 'martial arts') is one term for many possible activities. But the form and content, start and end, and inside and outside of activities that may or may not be called martial arts are interminably and incessantly up for disagreement and dispute. Some see judo as a martial art; others insist that it is really 'only' a sport. Some see taiji as a martial art; others argue that it is at best a kind of calisthenics, maybe even closer to a religion than to combat.

In and around the academic world, there are long-running battles around defining 'martial arts'. As mentioned, some have built up lists of criteria to be met before they will accept that this or that activity could be dignified with the term 'martial art'. Others have argued quite persuasively (and often using the criteria that the self-appointed gatekeepers of propriety have themselves proposed) that activities as unexpected as Star Wars-inspired Lightsaber combat, and indeed even certain forms of computer gaming, fulfil all of the criteria to be regarded as martial arts (Judkins 2016a; Goto-Jones 2016).

But, with no unequivocal definition or delimitation of martial arts, not to mention any agreement on pedagogy, motivations, outcomes or philosophy, where do we go? The obvious place to go in such a situation is the university. Universities are normally regarded as the places where disagreements and the attempt to find answers are welcomed and housed. However, one question has long recurred: Can martial arts ever be taken seriously and studied in the university as a legitimate subject, field or object of attention? (Bowman 2015a)

\section{Constructing Martial Arts Studies}

Whether martial arts can become a serious object of academic attention has long been a familiar question, especially to people whose interests straddle the worlds of martial arts and academia. Undoubtedly, for many who asked, it was widely assumed that the answer would always be no. No, martial arts cannot, could not, will not and would not be taken seriously within the university. And yet, research into this question actually returns a different answer. Digging deeper reveals that studies of martial arts have long appeared in all kinds of academic contexts and publications. Indeed, studies of martial arts can and do take place in all kinds of academic fields. Studies of martial arts have long appeared in fields as diverse as anthropology, film studies, law, management, philosophy, psychology, sociology, sports science, history, medicine, and more. 
Nonetheless, the question of whether martial arts can become a serious field of academic study in its own right is a very different matter (Bowman 2015a). The question of establishing a field is a very different thing to choosing a case study within a pre-existing field. It is eminently easy to imagine academic studies of just about anything: Farting, fidgeting, nose-picking, nail-biting you name it - could all be objects of study in any number of disciplines. Such studies could appear in almost any field, from anthropology to psychology to film to philosophy to history and beyond. However, it is quite another matter to propose that such a topic could or should mutate from being a specific object of study within a discipline, and morph into a disciplinary field in its own right.

Is there a call for fart studies, fidgetology, rhinopraxicology, or suchlike? There need to be pressing reasons for the development of a discrete new field - reasons based on answering some demand, filling a lack, redressing some kind of inadequacy or limitation. Answering a demand or responding to a lack has led to the emergence of many 'suffix-studies' subjects in recent decades: Cultural studies, media studies, gender studies, Afro-American and other ethnic identity studies, film studies, sports studies, management studies, postcolonial studies, and so on. The rationale for the development of a new subject always involves answering a need or a demand, by redressing a perceived lack or limitation in the present configuration of the disciplines. Researchers may find that a specific topic that they regard as important has inadequate space to develop within current disciplinary spaces, or that current approaches to it are inadequate or even stifling. Or a topic may simply be entirely absent, unrepresented, overlooked; and the development of ways to study it may not fit into any established disciplinary space.

All of the above-mentioned 'suffix-studies' subjects emerged in recent decades to fill a perceived gap. The driving forces for their development came from both inside and outside the university. Such fields endure, and research proliferates under their umbrellas, for as long as and to the extent that they adequately accommodate the direction of research questions. Taught courses in universities and colleges continue for as long as students turn up to take them and as long as they are deemed legitimate by the powers that be.

So, to what extent is there a demand or a need for an enduring field of martial arts studies? Can it really be something tangible and enduring? Is work that is currently being done under this title actually doing something unique, new or different, or are we really only ever dealing with discrete studies of martial arts organised by established disciplinary concerns? On the one hand, it is certain that there will always be studies of martial arts that can be straightforwardly positioned as fitting comfortably into established academic fields. There will be straightforward 'case studies' of martial arts that are written in film studies, literary studies, anthropology, psychology, area studies, history, sports studies, and so on. But, on the other hand, there are questions whose exploration entails breaking out of and moving beyond conventional disciplinary parameters. 
This kind of work can be difficult, particularly for scholars working in isolation. In the academic world, it is always safer and easier to stick to the established questions, methods, points of reference and protocols of discussion within a pre-established disciplinary field than to explore things differently, to explore different things, or to explore different things differently. Fortunately, many academics and scholars from many disciplines are now being drawn together under the umbrella or banner of 'martial arts studies', attending specific conferences and publishing in newly emergent journals and book series. The immediate effect of this is that people researching questions in and around martial arts are coming to feel less isolated and more able to locate or express their interests in terms of an emerging discourse.

The importance of developing a collectivity cannot be overstated. It is absolutely vital for researchers. On the one hand, it produces not just affiliations and supportive conversations, but also informed disagreement and focused criticisms, even rifts, all of which stimulate both circumspect and precise questions, argumentation, analysis and methods. On the other hand, it must be remembered that, in the university, if you cannot demonstrate what your research contributes to, then you cannot easily justify your activities. And if you cannot justify your activities then you will sooner or later encounter innumerable pressures to change them. There are certainly no funding opportunities available for projects that cannot relate their point, purpose and value to existing discourses.

So, the establishment of a discourse is essential to the production of meaningful work. As the psychoanalyst Jacques Lacan put it, the first signifier (the 'unary signifier') is always essentially meaningless or unintelligible. It is only when there is more than one - when there are binaries, iterations, reiterations, responses, differences, positions, and ultimately constellations - that meanings and values can start to be formed. Without a discourse, individual utterances will be taken to be nothing other than odd, eccentric, isolated, unintelligible, and therefore meaningless or irrelevant follies. A context of reception needs to be established.

Fortunately, in recent years, researchers have been attracted to martial arts studies conferences and to publishing in and reading self-consciously martial arts studies publications. This cross-disciplinary attraction to martial arts studies events and publications has enabled many kinds of discussions and interactions to take place across disciplinary divides, where before they would have been unlikely. Inevitably, this cross-fertilization has begun to produce thought and work that exceeds the confines of any one discipline. The net result is that different work is happening, completely new discussions are underway, organised by new questions, in new debates, generating all kinds of new knowledge.

In this sense, martial arts studies is the term for an interdisciplinary research nexus. A shared interest in the organising terms - all that is conjured up by the term 'martial arts' - is what holds the field together. I was about to say that 
a shared interest in martial arts is the 'glue' that binds it together, but I don't think that this is correct. We may not even agree on what the term designates or evokes. We may not agree on an approach to the object or field. Yet 'martial arts' provides the magnetism that draws researchers together. People are attracted to the field, because of a shared interest in what is perceived to be a shared object. Whether people stay within the field or not depends on whether they are stimulated by what they find in it (Bowman and Judkins 2017).

This is why martial arts studies has to be a circumspect, open, interested and interesting field of serious research, one that responds and speaks to a range of academic and cultural concerns, rather than being organised by too much certainty (Bowman and Judkins 2017). As Stuart Hall once argued, 'certainty stimulates orthodoxy' (Hall, Morley, and Chen 1996, 44), and orthodoxy is anathema to genuine thinking. I have argued elsewhere that too much certainty is surely one of the key reasons why so many earlier attempts to generate an academic field for the study of martial arts failed (Bowman and Judkins 2017).

In the end, the specific kind of certainty that scuppered earlier attempts to establish what we are today calling martial arts studies boiled down to certainty about what 'martial arts' is (or are). This is why I have always insisted on remaining open to what people think and feel and say 'martial arts' may mean. Hence, the academic study of martial arts should be open to the possibility of examining whatever people refer to as martial arts. However, at the same time as being entirely open to this, I am considerably less hospitable to most efforts to produce 'academic' definitions of martial arts. I do not mind the use of short-hand characterisations of the things we might be referring to when we say 'martial arts'. Nor do I mind the production of frameworks for grouping or distinguishing between practices. But I am resistant to any supposedly academic work that proposes a definition of martial arts and then only looks at things that fall into that definition. At best, this produces self-inflicted myopia, where one only sees what one wants to see. At worst, it produces the invention of theoretical worlds that bear no relation to anyone else's reality. I often encounter a feeling of suspicion in the face of many kinds of academic categories for precisely this reason: I tend to suspect that certain categories and frameworks neither reflect the world nor help us to gain insight into it, but rather invent a theoretical world. Certainly, the best academic categories, schemas, frameworks, and so on, can produce extremely useful ways of conceptualising and grasping reality. But bad categories can actually stop us from seeing reality.

This is why I have so often argued against definition (Bowman 2017d, 2017c, 2017b), and will do so again in Chapter Two. For, first, definition itself often seems more disabling than enabling, at least when it comes to my concerns about the places and functions of martial arts in culture. (Moreover, I often suspect that the drive to define reveals a drive to control, by policing things into categories and hierarchies, which the definer often seems to want to control.) Second, definition often seems 'logically' self-defeating. After all, 
if you already claim to know in advance what 'martial arts' are, then why would you need to study them academically? If you have already decided what they are, then you have already implicitly decided how to study them. So, the production of knowledge about them will always be the production of the 'same-old, same-old'. This is why Donn Draeger's 'hoplology' project failed. It already claimed to know, in advance, what it was studying. This is why sociobiological and social Darwinist approaches strike me as fairly feeble too. If everything must be as it is for evolutionary advantage, then that can only mean that we can all pack up early and go home - as if everything's been solved and resolved!

No. Quite other than this, martial arts studies does not need a definition of martial arts, nor indeed a strong attachment to a specific orientation of study. In fact, fixation on either of these points will curtail it. Martial arts studies needs to be responsive to the actual practices, discourses, institutions, agents and agencies that operate under the term or using the category 'martial arts'. What we will find under the term will take variable forms, depending on time, place and context. The social, cultural and even political status of each instance or (re)iteration of 'martial arts' will have multiple dimensions, and will be fruitful for multiple types of enquiry.

The kinds of enquiry carried out by a sociologist will differ from that of a psychologist, semiotician or historian. Each form of enquiry produces specific genres and orientations of insight. Indeed, because of this, once again we might say that the kind of object constructed by various different genres of disciplinary attention produces yet another construct, also called 'martial arts'. Different academic discourses produce a different 'disciplinary object' (Bowman 2015a, 2007; see also Mowitt 1992), even if they each have the same name. Even 'the same' martial art becomes something quite different when it is put under the lens of the psychologist to when it is put under the lens of the philosopher or that of the historian or that of the ethnologist, and so on. Each different discourse, each different manifestation, is a result of different combinations of elements, different emphases, different inclusions and exclusions.

In discussing 'martial arts' in different contexts or discourses, then, one is inevitably going to be discussing different things, different constructs. Saying this might reopen the charge of relativism. But context is always everything universally. Everything is relative, always. But one thing stays the same: For the martial arts practitioner and for the martial arts researcher, martial arts are an 'object of knowledge', not an 'object of consumption' (Spatz 2015). They are not used up in one moment of consumption, the way a matchstick is finished and worthless a few seconds after it has been struck. Rather, they are infinitely and infinitesimally expansive; ever unfolding; ever familiar yet ever mysterious and enigmatic (Mroz 2017). There is always more to work out, always more to be gained, whether in the form of moving into new fields and unexplored terrain, or whether in the form of unearthing the internal foreign territories' of that which is supposedly familiar, by deconstructing what is 
supposedly 'well-known'. As Hegel put it, and as I have felt compelled to repeat on multiple occasions: "What is "familiarly known" is not properly known, just for the reason that it is "familiar" ... [Familiarity itself] is the commonest form of self-deception' (Hegel 2005, 35; cf. Bowman 2010d, 45, 58).

\section{The Construction of this Book}

In what follows, Chapter One engages with the question of whether martial arts and the emergent field of martial arts studies should be regarded as trivial. In doing so, it explores possible rationales and raisons d'etre of the field in terms of a reflection on the legitimation of academic subjects, especially those closest to martial arts studies and from which martial arts studies can be seen to have emerged. It argues that the designation of martial arts as trivial reflects a specific Western popular cultural history with connections to orientalism (Bowman 2013b; see also Lo 2005). This evinces not only specific cultural values but also the complex economy of forces that structure cultural outlooks and interpretations. Specifically, the chapter considers representations and strategies by which martial arts ideas and images have become trivial in Western popular culture. In so doing, the chapter further illustrates the value of deconstruction as an analytical approach to culture and its practices.

Chapter Two argues against all forms of scientism and the widespread perceived need to define martial arts in order to study martial arts or 'do' martial arts studies. It argues instead for the necessity of theory before definition, including theorisation of the orientation of the field of martial arts studies itself. Accordingly, the chapter criticises certain previous (and current) academic approaches to martial arts, particularly the failed project of hoplology. It then examines the much more promising approaches of current scholarship, such as that of Sixt Wetzler, before critiquing certain aspects of its orientation. Instead of accepting Wetzler's 'polysystem theory' approach uncritically, the chapter argues instead for the values of a poststructuralist 'discourse' approach in martial arts studies.

Chapter Three begins to deconstruct the idea that martial arts are purely physical or embodied practices. It does so by focusing on the contexts, forces and structures outside of embodied practices that influence, inform or even orientate physical culture in myriad complex ways. It approaches these in terms of Jacques Derrida's notion of the supplement. This notion has already been touched upon earlier in the Introduction (above), but Chapter Three is the first chapter in which its full deconstructive potential will be explored.

Chapter Four presents embodiment as a uniquely challenging problem for certain traditions and approaches to scholarship, particularly those that are implicitly or explicitly organised by the aim of establishing meanings. Such an orientation is exemplified by semiotics, of course, but the chapter argues 
that even approaches designed to critique semiotics and other forms of 'logocentrism' (i.e., approaches that focus on words and meanings) ultimately struggle in the face of dealing with aspects of embodiment. Even Derridean deconstruction - which was developed as a strident critique of logocentrism struggles to move beyond the focus on words and meanings. So, the question becomes one of whether scholars interested in embodiment should reject or move beyond approaches like deconstruction.

Drawing on a loosely autobiographical narrative that touches on aspects both of my own academic training and my investment in martial arts and other physical cultural practices, this chapter argues that it is not simply possible to 'reject' or 'move beyond' the logocentrism of traditional 'search for meaning' orientations. It argues that, even though this observation may seem relatively passé to some, 'embodiment' is still very productively conceived of as 'embodiment of' - i.e., as the embodiment of something else; specifically, as the performative and interpretive elaboration of something other that is received, perceived, felt, constructed, believed, assumed or otherwise lived as being either an aim, ideal, desire, objective, fantasy, or as a norm, or indeed as the warding off of something undesired or feared. The chapter poses questions of how to 'capture', 'convey' or 'communicate' embodiment in words, and it interrogates the necessity of the current hegemony of the written word in academia. However, it seeks to avoid any kind of evangelism about new approaches or understandings of embodiment, and twists around at the end to propose that even certain forms of what we perhaps too quickly regard as 'enlightening' or 'emancipating' practices and techniques of embodiment might be regarded as traps, or indeed prisons.

In a different way, our understanding of culture and history may also amount to a kind of trap. Certainly, embodiment is always supplemented by the semiotic, and the emergence of martial arts discourses and practices in the West has to be assessed against the backdrop of a complex cultural history. Accordingly, Chapter Five explores the mid to late $20^{\text {th }}$ Century explosion in the circulation of ideas connected with Taoism and Zen (Chan) Buddhism in Western popular culture. It argues that the introduction of ostensibly Chinese and Japanese philosophical notions into Western contexts and consciousnesses was never a simple act of transparent cross-cultural communication, from East to West. Rather, it always involved huge imaginative leaps and complex processes of projection, translation and transformation.

With reference to examples such as the hippy counterculture, the films and writings of Bruce Lee, the TV series Kung Fu (1972-1975), and others, the chapter argues that Western popular cultural encounters with ideas, ideals and conceptual universes like those of Taoism were always 'in bits'. However, it insists that this is not a negative or bad thing, and that, in fact, thinking about the ways in which ideas and practices travel and how they transform, over time and place, across cultures and within cultures, can teach us a great deal about 
how culture and communication always 'work' - or don't - and what we might make of such fragmentation and complexity.

The connections between Eastern martial arts and (embodied) philosophy are strong. Often ideas and associations involve images of calm detachment and tranquillity. Chapter Six deconstructs these images and the ways they function in contemporary discourses. It explores a range of connections and associations, from ideas of Zen Buddhist meditation to contemporary mindfulness and from Samurai to kamikaze themes as they have related to various kinds of militarism and the explicit outlook of Norwegian mass-murderer Anders Behring Breivik. It does so in order to demonstrate the ideological, political and ethical complexity (indeed, undecidability) of martial arts discourse vis-àvis serenity, psychopathy, sanity and insanity.

But, after putting madness on the table, where can we go? How are martial arts regarded in the wider world, outside of martial arts contexts 'proper'? Derrida and other proponents of deconstruction would often engage issues tangentially or transversally, focusing on 'minor' or 'marginal' dimensions - things that lie on the outer limits of supposed relevance. Following this deconstructive approach, Chapter Seven examines conversations, dialogues and statements about martial arts in films that can by no stretch of the imagination be regarded as martial arts films.

The chapter takes this unusual focus in order to glean unique insights into the status of martial arts in mainstream popular culture. It is interested in the ways that martial arts are understood, positioned, and given value within the wider flows, circuits, networks or discourses of culture. Films examined include Lolita (1962), Roustabout (1964), Rollerball (1975), The Wanderers (1979), An Officer and a Gentleman (1982), Trading Places (1983), Vision Quest/Crazy for You (1985), Full Metal Jacket (1987), Once Were Warriors (1994), Napoleon Dynamite (2004), and Meet the Fockers (2004); and some discussion is given to 'limit cases' - action films such as Lethal Weapon (1987) and The Matrix (1999).

The analysis suggests that martial arts tend to be represented in non-martial arts films audiovisually, and that on the rare occasions martial arts are discussed they tend to emerge as improper or culturally unusual activities or practices. Because of their familiar yet non-normal (unhomely/unheimlich, uncanny) status, along with their entwinement in senses of lack and related fantasies and desires, martial arts in these contexts are frequently related to matters of sexuality, insecurity and the desire for plenitude. Accordingly, although occasionally associated with higher cultural values such as dignity, martial arts are more often treated as comic, uncanny or perverse aberrations from the norm.

After so many different approaches to issues in and around martial arts, the conclusion begins by reflecting on the diversity and range of directions from, into, around, out of, and out into which studies could develop. It poses the question of how and why, where and when we draw lines in our studies, whether of/around 'martial arts' and/or any other subject. In deconstruction, the question of drawing the line is often treated as contingent, conventional, 
consequential and political. It is often thematised as 'violent' in its own right. Nonetheless, for multiple reasons, 'drawing the line' is both necessary and inevitable. Accordingly, the conclusion sets out some of the key implications relating to where, when, how and why academics draw the line in their foci and approaches, specifically in martial arts studies, but also in critical, intellectual and academic endeavours more widely. 
